\title{
Nutrition and immune function in human immunodeficiency virus infection
}

\author{
Derek C. Macallan \\ Division of Infectious Diseases, St George's Hospital Medical School, Cranmer Terrace, London SW17 ORE, UK
}

\begin{abstract}
The triad of human immunodeficiency virus (HIV) infection, nutritional status and immune function are intimately related, each factor having effects on the others. The dominant effect in this three-way relationship is the effect of HIV infection on nutritional status, an effect which, until the advent of potent anti-retroviral drugs, has been manifest primarily as wasting. Recently, more complex metabolic abnormalities have become apparent, particularly fat redistribution syndromes, hyperlipidaemia and hypercholesterolaemia. For the converse effect, the effect of nutritional state on HIV disease progression, there is good evidence that clinical outcome is poorer in individuals with compromised nutrition. However, the beneficial effects of nutritional support have been more difficult to demonstrate. For macronutrients, effective macronutrient supply improves survival in severely-malnourished individuals and may have beneficial effects in lessseverely-affected individuals. Micronutrient deficiencies appear to be involved in modifying clinical HIV disease and may also be associated with enhanced mother-to-child transmission of virus, particularly in developing countries. Intervention trials in this setting are currently under way. In conclusion, the interaction of HIV infection and nutrition is of great importance not just because of the major impact that HIV infection has on nutritional state, but also because strategies to improve nutritional status, both quantitatively and qualitatively, may have a beneficial effect on the clinical and immunological course of the disease.
\end{abstract}

HIV infection: AIDS: Nutritional status: Wasting: Micronutrients

The interaction between human immunodeficiency virus (HIV) infection, nutrition and immune function forms a very complex relationship in which most variables interact in a bidirectional manner with most other variables. This relationship is illustrated in Fig. 1. The dominant effect in this triangular model is the effect of HIV infection on nutritional state, and it is in this area that most information

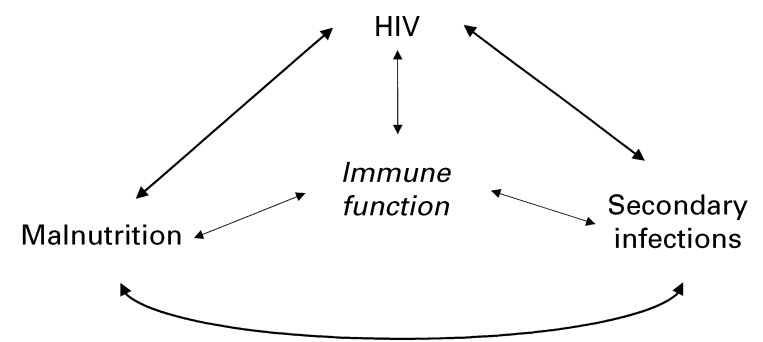

Fig. 1. Model of interaction of human immunodeficiency virus (HIV) infection, nutritional state and immune function. has become available (Macallan, 1998). Our understanding of the converse relationship, the impact of nutritional status on immune function and disease progression, is much less clear and the data in this area are more confusing.

I would first like to address the effect of HIV infection on nutritional state, and then consider issues relating nutritional state to HIV disease progression, particularly addressing the question as to whether alterations in nutritional state can influence clinical outcome.

\section{The impact of human immunodeficiency virus on nutritional state}

Wasting in human immunodeficiency virus infection

Until a few years ago, when effective anti-retroviral treatment became available, the dominant clinical nutritional effect of HIV was wasting. In recognition of the clinical importance of wasting in HIV disease progression, unexplained weight loss was included as an acquired

\footnotetext{
Abbreviations: AIDS, acquired immune deficiency syndrome; HAART, highly-active anti-retroviral therapy; HIV, human immunodeficiency virus. Corresponding author: Dr D. C. Macallan, fax +44 (0)181 725 3487, email macallan@sghms.ac.uk
} 
immune deficiency syndrome (AIDS)-defining diagnosis in the Centers for Disease Control (1987) criteria for AIDS. In some individuals with HIV infection wasting occurs progressively over long periods of time, often over many years, and such chronic progressive wasting is often associated with chronic gastrointestinal disease (Macallan et al. 1993). In our experience, a more common pattern of wasting is characterized by acute intermittent episodes of weight loss lasting several weeks or months at a time. Such acute episodes of wasting are often associated with acute opportunistic infections (Fig. 2; Macallan et al. 1993). Fortunately, such infective episodes have become less common since the widespread introduction of prophylactic anti-infectives such as co-trimoxazole which has dramatically reduced the incidence of pneumocystis carinii pneumonia. From patterns of weight change similar to that seen in Fig. 2, one may make a number of observations regarding the pathophysiology of HIV-related wasting. First, HIV per se does not necessarily induce a wasting state. Infected subjects may remain weight stable for many years, even in the absence of anti-retroviral treatment. Second, opportunistic infections appear to be a major precipitant of weight loss, and their prevention, diagnosis and prompt treatment are therefore of major importance in preventing wasting. Third, anabolism or weight recovery is still possible in such patients with effective treatment of the secondary precipitating event (Macallan et al. 1993).

Underlying such wasting are a number of metabolic disorders which HIV appears to induce. All areas of intermediary metabolism appear to be affected, including energy balance, carbohydrate metabolism, protein metabolism and lipid metabolism, although the relative contributions of each remains unclear (Macallan, 1998). A full discussion is not possible here, but abnormalities such as accelerated wholebody protein turnover, altered carbohydrate metabolism and hyperlipidaemia are characteristic of infection (Hommes et al. 1991a,b; Grunfeld et al. 1992; Hellerstein et al. 1993; Macallan et al. 1995a). However, the final common denominator of wasting must be negative energy balance. Our studies of energy balance in HIV-infected individuals, albeit in the era before effective anti-retroviral treatment,

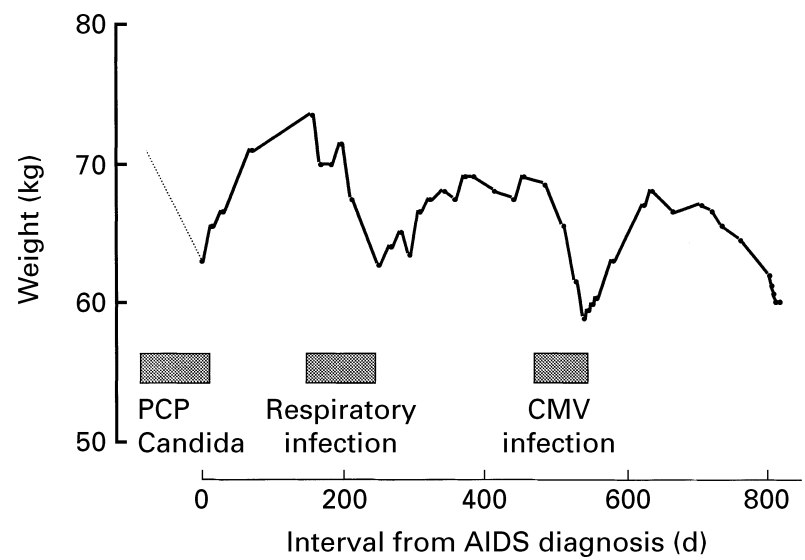

Fig. 2. Acute weight loss episodes in an individual with human immunodeficiency virus infection progressing to acquired immune deficiency syndrome (AIDS). PCP, pneumocystis carinii pneumonia; CMV, cytomegalovirus. (From Macallan et al. 1993.) demonstrated that weight loss is the consequence not of accelerated or excessive energy expenditure but a consequence of reduced energy intake (Macallan et al. 1995b; LA Sheehan, DC Macallan \& GE Griffin, unpublished results). Such observations demonstrate the importance of maintaining energy intake in managing patients with HIV infection (Fig. 3).

\section{Anti-retroviral therapy and nutritional state}

Recently there have been major changes in the clinical face of HIV infection, and we have now entered the era of so-called 'highly-active anti-retroviral therapy' (HAART). The full impact of such therapy on wasting is yet to be seen, but several early studies have been published. Weight recovery is frequently seen in patients responding to HAART (Force et al. 1997; Teixeira et al. 1997; Silva et al. 1998; Stricker \& Goldberg, 1998). However, in most studies there are still some individuals who fail to gain weight or still continue to lose weight. For example, in a large study of patients commencing treatment with indinavir, after a median of $176 \mathrm{~d}$ on treatment, body weight had increased in 119 of 160 patients $(74.4 \%)$, had not changed in thirteen $(8.1 \%)$ and had fallen in twenty-eight $(17.5 \%)$, relative to baseline (Carbonnel et al. 1998). Furthermore, some investigators have found that cohorts of patients starting antiretroviral therapy, including a protease inhibitor, fail to regain weight as a whole group (Fig. 4; Schwenk et al. 1999). This overall lack of a positive trend masks the observation that some individuals in the cohort did gain weight after commencing therapy. At 14 weeks $13 \%$ (n 8) of the patients showed a positive weight gain trend $(>5 \% / 100 \mathrm{~d})$ and at 28 weeks this percentage had risen to $21(n 13)$. However, at the same time points $3 \%(n 2)$ and 11 $\%(n 7)$ of the patients respectively demonstrated significant (> $5 \% / 100 \mathrm{~d}$ ) negative weight trends (Schwenk et al. 1999).

Thus, it appears that even in the era of HAART wasting does continue to remain a clinical problem, albeit far less commonly than previously, and may become more of a problem if viral resistance to such drugs becomes an increasing clinical complication.

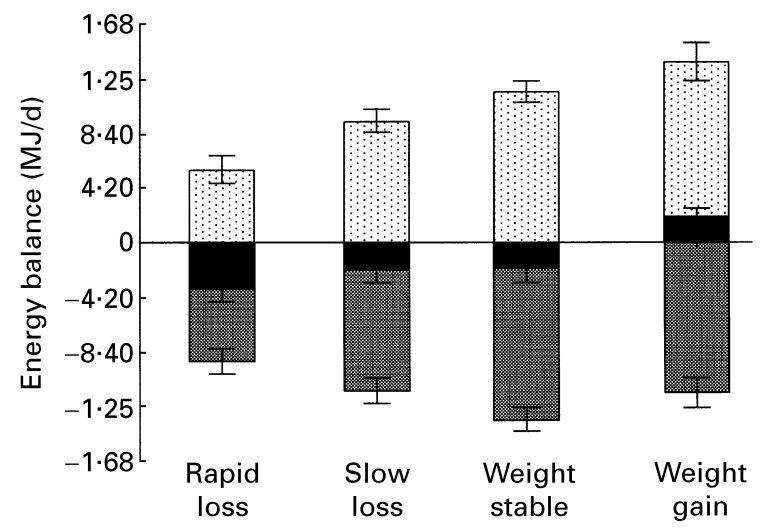

Fig. 3. Relationship between energy expenditure, energy intake and weight loss in patients with AIDS. (). Intake; ( $\square$ ), balance; ( expenditure. Values are means and standard deviations represented by vertical bars for the following no. of patients: rapid loss $n 7$, slow loss $n 21$, weight stable $n 16$, weight gain $n$ 7. (From Macallan et al. 1995b.) 


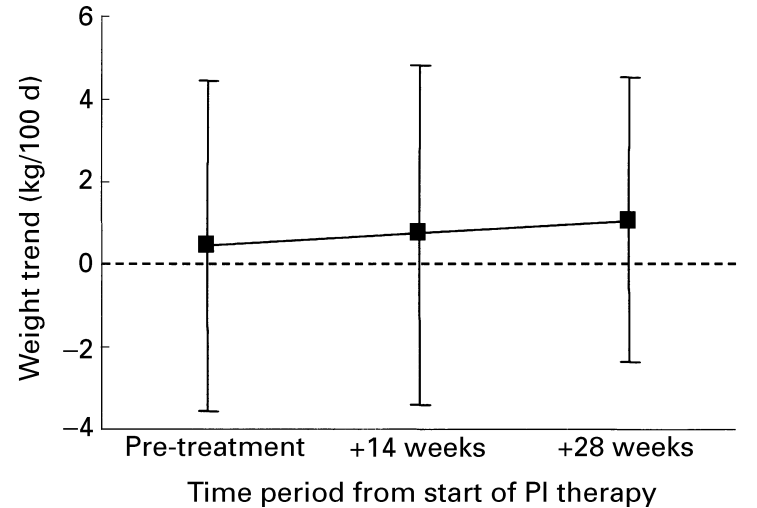

Fig. 4. Impact of initiation of highly-active anti-retroviral therapy on weight trend in patients with human immunodeficiency virus infection. Pl, protease inhibitor. Values are means and standard deviations represented by vertical bars for twenty-four patients. (From Schwenk et al. 1999.)

Even when HAART does restore body mass, not all metabolic abnormalities are reversed. Recently a new constellation of metabolic abnormalities have been recognized in treated HIV patients, which have been collectively termed lipodystrophy (Carr et al. 1998a). The features of this syndrome include the redistribution of body fat away from subcutaneous areas, particularly facial fat deposits, with a concurrent accumulation of fat in the visceral compartment or in the dorso-cervical fat pad (Carr et al. 1998b; Lo et al. 1998; Miller et al. 1998). As a consequence, abdominal swelling may develop, whilst peripheral tissues such as limbs and face become grossly 'wasted'. At the same time, plasma triacylglycerols are often grossly increased, sometimes dramatically, to levels at which pancreatitis is likely (Henry et al. 1998b; Sullivan et al. 1998). In addition, there are reports of premature atherosclerosis in individuals on HAART (Behrens et al. 1998; Gallet et al. 1998; Henry et al. 1998a; Laurence, 1998; Vittecoq et al. 1998). Thus, it appears that, although anti-retroviral treatment does result in clinical improvement in overall nutritional state, not all metabolic abnormalities are reversed, and patients on therapy may still require further investigation and management of their metabolic syndrome.

\section{The impact of nutrition on human immunodeficiency virus disease}

\section{Nutrition and human immunodeficiency virus disease progression}

The impact of nutrition on HIV disease is a part of the model (Fig. 1) which is more difficult to define. In order to address this aspect, let us first consider whether an effect of malnutrition on HIV disease progression can be demonstrated. Early in the HIV epidemic Kotler et al. (1989) observed a relationship between loss of lean body mass and timing of death in patients with AIDS. They demonstrated that many patients with AIDS died at a level of malnutrition barely compatible with life, and speculated that the degree of malnutrition may have been key in determining the final clinical course and death of such patients. Such an impact of nutritional state on survival was elegantly shown by Suttmann et al. (1995), who demonstrated an independent effect of loss of body cell mass on survival. More recently, the Community Programs for Clinical Research in AIDS have demonstrated that a weight-losing trend predicts subsequent mortality and susceptibility to opportunistic infections (Wheeler et al. 1998). Thus, there does appear to be evidence that impaired nutritional state adversely influences disease progression.

If malnutrition does accelerate the progress of HIV infection, it might be argued that improving nutritional state may improve clinical outcome. Although this situation appears to be implicitly true from the evidence mentioned previously, it has been much harder to demonstrate such an effect at the clinical level. There is a wide literature addressing this question, but many of the results are difficult to interpret as a result of having either poor or absent controls or inappropriate outcome measures. There are many difficulties associated with assessing the effect of nutritional intervention on HIV, not least because of the dramatic effects of other factors such as the presence or absence of opportunistic infections, the impact of drug treatment, and environmental, social and psychological factors. It is quite possible that even if a particular nutritional intervention had a major effect, it might not be 'visible' through the confounding 'smokescreen' of these many other factors. Despite this situation, several studies do address the question of whether nutrition intervention has an impact on clinical outcome, and I will cite examples to illustrate the findings.

\section{Modification of the inflammatory response}

One area of interest is whether nutrients can be used to modify the inflammatory response to HIV infection. $n-3$ Fatty acids are known to have an anti-inflammatory effect. One large clinical trial of such fatty acids in patients with AIDS had a disappointing impact on clinical outcome, having no effect on weight trend or serum cytokines, even though triacylglycerol concentrations were modified, as expected (Hellerstein et al. 1996).

\section{Micronutrients and human immunodeficiency virus disease}

The impact of micronutrients on HIV disease progression has also been an area of great interest. Several studies have shown an association between disease progression and micronutrient status. For example, Baum et al. (1995) showed an association between development of vitamin $\mathrm{A}$ or $\mathrm{B}_{12}$ deficiency with a reduction in $\mathrm{CD} 4+$ cell count; conversely they found that normalization of vitamin $\mathrm{B}_{12}$, or indeed $\mathrm{Zn}$, was associated with an increase in $\mathrm{CD} 4+$ cell count. However, there are difficulties in interpreting plasma vitamin levels, particularly since they are affected by the acute-phase response and are susceptible to changes in binding proteins. Similarly, there are difficulties in interpreting the impact on clinical outcome when surrogate markers such as CD4+ cell count are used as indices of efficacy. Some investigators have chosen to look at micronutrient intake rather than plasma levels. For example, Tang et al. (1993) demonstrated that high intakes of vitamin $\mathrm{C}$, thiamin or 
niacin were associated with a reduced relative risk of disease progression, whereas high intakes of $\mathrm{Zn}$ were associated with an increased risk of disease progression. Vitamin A intake appeared to have a 'U'-shaped relationship with outcome, both very high and very low intakes being associated with poorer outcome (Tang et al. 1993).

Certainly, it does appear that some individuals with HIV infection develop moderate to severe micronutrient deficiency, and that this deficiency affects their clinical state; such patients should clearly receive adequate vitamin supplementation. Extrapolating such selective use of vitamin supplements to universal supplementation for all HIV-infected individuals is a strategy which is more difficult to justify from the available evidence. However, large clinical studies designed to prove the value of universal supplementation are almost impossible to perform in the current changing clinical climate and are unlikely to be forthcoming. Micronutrients, of course, are normally ingested with macronutrients as part of food; wasting, which by definition is indicative of macronutrient deficiency, is therefore likely to be a useful marker of micronutrient deficiency and thus, in my opinion, it is wasting patients who should be selectively targeted for micronutrient supplementation.

\section{Micronutrients and mother-to-child transmission of human immunodeficiency virus}

One area of particular interest in terms of the place of micronutrients in HIV disease is their potential role in modifying mother-to-child transmission of HIV around the time of childbirth. This possibility is particularly pertinent in the developing world where vertical transmission is a common mode of transmission, and where such interventions are affordable compared with very expensive anti-retroviral therapy. A recent study from Africa showed that vitamin A deficiency was very common among pregnant women, and that the degree of deficiency correlated strongly with the risk of transmission from mother to baby (Fig. 5; Semba et al. 1994). Comparable results were observed in a similar study in two metropolitan areas in the USA (Greenberg et al. 1997). These observations have given rise to several interventional trials, the results of which are still awaited. One trial has now published the results of pregnancy outcome (but not HIV transmission which requires a longer follow-up period; Fawzi et al. 1998). Groups received multivitamin supplementation and/or vitamin A supplementation. Surprisingly, vitamin A supplementation alone appeared to have no impact on pregnancy outcome, whereas multivitamin supplementation did have a major impact in terms of fetal death, low birth weight, preterm birth and low weight-for-age (Table 1). Hopefully, the role and relative contributions of different vitamin supplementation strategies (multivitamins, vitamin $\mathrm{A}$, etc.) should become clearer as several studies in the developing world reach completion in the next few years.

\section{Macronutrient supply in severe malnutrition}

Although there are many exciting possibilities for ways in which nutritional intervention may impinge on HIV disease progression in a positive way, no consensus has yet emerged from the results of intervention studies to date, particularly those studies involving micronutrient supplementation.

However, one area where nutritional intervention can be shown to have clear benefit is in those individuals with severe malnutrition and wasting in whom provision of adequate nutrition may have a dramatic effect on survival. This benefit was recently demonstrated by a French study of severely-malnourished patients receiving total parenteral nutrition. In such patients survival was improved from 57 to $211 \mathrm{~d}$ (Melchior et al. 1997). Several other studies have

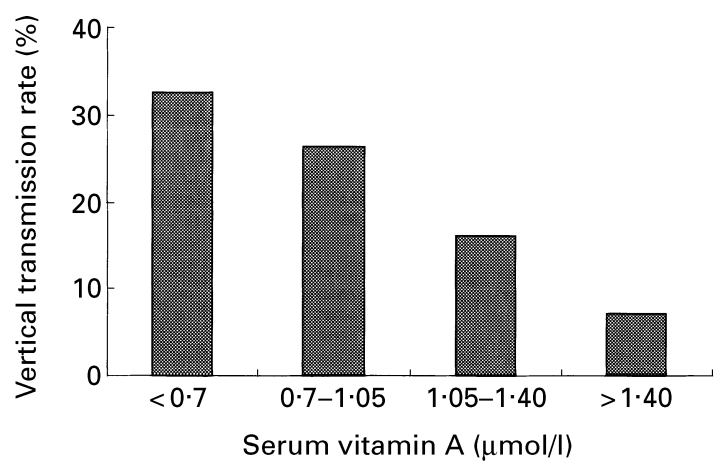

Fig. 5. Vitamin A status and risk of mother-to-child transmission of human immunodeficiency virus. (From Semba et al. 1994.)

Table 1. Effect of multivitamin (MV) and vitamin (vit) A supplementation during pregnancy in human immunodeficiency virus-infected women in Tanzania.* (from Fawzi et al. 1998)

\begin{tabular}{|c|c|c|c|c|c|c|}
\hline & \multicolumn{4}{|c|}{ MV } & \multirow{2}{*}{\multicolumn{2}{|c|}{ Vit A }} \\
\hline & $\begin{array}{l}\text { Relative risk of adverse } \\
\text { outcome }\end{array}$ & \multicolumn{2}{|c|}{$95 \% \mathrm{Cl}$} & $\begin{array}{c}\text { Statistical significance: } \\
P\end{array}$ & & \\
\hline \multicolumn{7}{|l|}{ Child variables } \\
\hline Fetal death & 0.61 & \multirow{4}{*}{\multicolumn{2}{|c|}{$\begin{array}{l}0.39-0.94 \\
0.38-0.82 \\
0.38-0.96 \\
0.39-0.82\end{array}$}} & 0.02 & \multirow{4}{*}{\multicolumn{2}{|c|}{$\begin{array}{l}\text { NS }(P=0.59) \\
\text { NS }(P=0.54) \\
\text { NS }(P=0.70) \\
\text { NS }(P=0.29)\end{array}$}} \\
\hline Low birth weight $(<2500 \mathrm{~g})$ & 0.56 & & & 0.002 & & \\
\hline Preterm birth (<37 weeks) & 0.61 & & & 0.03 & & \\
\hline Small-for-gestational age & 0.57 & & & 0.002 & & \\
\hline \multirow{2}{*}{$\begin{array}{l}\text { Maternal variables } \\
\text { Maternal CD4+ } \\
\text { Change at } 6 \text { weeks post partum }\end{array}$} & MV & no $M V$ & $P \dagger$ & Vit A & No vit $A$ & $P+$ \\
\hline & +167 & +112 & $<0.001$ & +142 & +138 & $0 \cdot 13$ \\
\hline
\end{tabular}

* The study included 1075 pregnant women randomized to four arms: placebo; multivitamin (no vitamin A); vitamin A; multivitamin with vitamin A. † Statistical significance of difference. 
demonstrated the importance of nutritional support in severe macronutrient deficiency, and this is an area which should not be neglected.

\section{Conclusion}

The interaction of nutrition, immunity and HIV is clearly both complex and important. The impact of HIV infection on nutritional state is marked and has been a major clinical feature of the disease for many years. The pattern of metabolic changes seen is altering, particularly with the advent of potent drugs active against HIV, which may have their own metabolic impact. Nutritional intervention represents one potential means to modify disease progression. In terms of micronutrients much of the evidence remains unclear, but the impact of vitamin A and multivitamins in the developing world is an area of great clinical importance, and new information is currently emerging. Where there is macronutrient deficiency there now appears to be no doubt that appropriate nutrition support can have a major impact on morbidity and mortality; such support may also result in improvements in immune function, as discussed earlier in this meeting (Chandra, 1991, 1997; RK Chandra, personal communication).

\section{References}

Baum MK, Shor-Posner G, Lu Y, Rosner B, Sauberlich HE, Fletcher MA, Szapocznik J, Eisdorfer C, Buring JE \& Hennekens CH (1995) Micronutrients and HIV-1 disease progression. AIDS 9, 1051-1056.

Behrens G, Schmidt H, Meyer D, Stoll M \& Schmidt RE (1998) Vascular complications associated with use of HIV protease inhibitors. Lancet 351, 1958.

Carbonnel F, Maslo C, Beaugerie L, Carrat F, Wirbel E, Aussel C, Gobert JG, Girard PM, Gendre JP, Cosnes J \& Rozenbaum W (1998) Effect of indinavir on HIV-related wasting. AIDS 12, $1777-1784$.

Carr A, Samaras K, Burton S, Law M, Freund J, Chisholm DJ \& Cooper DA (1998a) A syndrome of peripheral lipodystrophy, hyperlipidaemia and insulin resistance in patients receiving HIV protease inhibitors. AIDS 12, F51-F58.

Carr A, Samaras K, Chisholm DJ \& Cooper DA (1998b) Pathogenesis of HIV-1-protease inhibitor-associated peripheral lipodystrophy, hyperlipidaemia, and insulin resistance. Lancet 351, 1881-1883.

Centers for Disease Control (1987) Revision of the CDC case surveillance definition for acquired immunodeficiency syndrome. Mortality and Morbidity Weekly Review 36, Suppl. 1S, 3S-14S.

Chandra RK (1991) Nutrition and immunity: lessons from the past and new insights into the future. American Journal of Clinical Nutrition 53, 1087-1101.

Chandra RK (1997) Nutrition and the immune system: an introduction. American Journal of Clinical Nutrition 66, 460S463S.

Fawzi WW, Msamanga GI, Spiegelman D, Urassa EJ, McGrath N, Mwakagile D, Antelman G, Mbise R, Herrera G, Kapiga S, Willett W \& Hunter DJ (1998) Randomised trial of effects of vitamin supplements on pregnancy outcomes and $\mathrm{T}$ cell counts in HIV-1-infected women in Tanzania. Lancet 351, 1477-1482.

Force G, Jockey C, Tugler MH, Khayat G \& Champetier de Ribes D (1997) Characteristics of change in body composition with efficiency of antiretroviral treatment in AIDS patients. Nutrition 13, 290.

Gallet B, Pulik M, Genet P, Chedin P \& Hiltgen M (1998) Vascular complications associated with use of HIV protease inhibitors. Lancet 351, 1958-1959.

Greenberg BL, Semba RD, Vink PE, Farley JJ, Sivapalasingam M, Steketee RW, Thea DM \& Schoenbaum EE (1997) Vitamin A deficiency and maternal-infant transmissions of HIV in two metropolitan areas in the United States. AIDS 11, 325-332.

Grunfeld C, Pang M, Doerrler W, Shigenaga JK, Jensen P \& Feingold KR (1992) Lipids, lipoproteins, triglyceride clearance, and cytokines in Human Immunodeficiency Virus infection and the Acquired Immunodeficiency Syndrome. Journal of Clinical Endocrinology and Metabolism 74, 1045-1052.

Hellerstein MK, Grunfeld C, Wu K, Christiansen M, Kaempfer S, Kletke C \& Shackleton CHL (1993) Increased de novo hepatic lipogenesis in human immunodeficiency virus infection. Journal of Clinical Endocrinology and Metabolism 76, 559-565.

Hellerstein MK, Wu K, McGrath M, Faix D, George D, Shackleton CH, Horn W, Hoh R \& Neese RA (1996) Effects of dietary $n-3$ fatty acid supplementation in men with weight loss associated with the acquired immune deficiency syndrome: Relation to indices of cytokine production. Journal of Acquired Immune Deficiency Syndrome and Human Retrovirology 11, 258-270.

Henry K, Melroe H, Huebesch J, Hermundson J, Levine C, Swensen \& Daley J (1998a) Severe premature coronary artery disease with protease inhibitors. Lancet 351, 1328.

Henry K, Melroe H, Huebesch J, Hermundson J \& Simpson J (1998b) Atorvastatin and gemfibrozil for protease-inhibitorrelated lipid abnormalities. Lancet 352, 1031-1032.

Hommes MJT, Romijn JA, Endert E, Schattenkerk JKME \& Sauerwein HP (1991a) Basal fuel homeostasis in symptomatic human immunodeficiency virus infection. Clinical Science 80, 359-365.

Hommes MJT, Romijn JA, Endert E, Schattenkerk JKME \& Sauerwein HP (1991b) Insulin sensitivity and insulin clearance in Human Immunodeficiency Virus-infected men. Metabolism 40, 651-656.

Kotler DP, Tierney AR, Wang J \& Pierson RN (1989) Magnitude of body-cell-mass depletion and the timing of death from wasting in AIDS. American Journal of Clinical Nutrition 50, 444-447.

Laurence J (1998) Vascular complications associated with use of HIV protease inhibitors. Lancet 351, 1960.

Lo JC, Mulligan K, Tai VW, Algren H \& Schambelan M (1998) 'Buffalo hump' in men with HIV-1 infection. Lancet 351, 867870.

Macallan DC (1998) Metabolic abnormalities and wasting in human immunodeficiency virus infection. Proceedings of the Nutrition Society 57, 373-380.

Macallan DC, McNurlan MA, Milne E, Calder AG, Garlick PJ \& Griffin GE (1995a) Whole body protein turnover from leucine kinetics and the response to nutrition in Human Immunodeficiency Virus infection. American Journal of Clinical Nutrition 61, 818-826.

Macallan DC, Noble C, Baldwin C, Foskett M, McManus T \& Griffin GE (1993) Prospective analysis of patterns of weight change in stage IV human immunodeficiency virus infection. American Journal of Clinical Nutrition 58, 417-424.

Macallan DC, Noble C, Baldwin C, Jebb SA, Prentice AM, Coward WA, Sawyer MB, McManus TJ \& Griffin GE (1995b) Energy expenditure and wasting in Human Immunodeficiency Virus infection. New England Journal of Medicine 333, 83-88.

Melchior JC, Gelas P, Carbonnel F, Zazzo JF, Henzel D, Cosnes J, Bouletreau P \& Messing B (1997) Improved survival by home Total Parenteral Nutrition in AIDS patients: Follow up of a controlled randomized prospective trial. Nutrition 13, 272 Abstr. 
Miller KD, Jones E, Yanovski JA, Shankar R, Feuerstein I \& Falloon J (1998) Visceral abdominal fat accumulation associated with use of indinavir. Lancet 351, 871-875.

Schwenk A, Kremer G, Cornely O, Diehl V, Fatkenheuer G \& Salzberger B (1999) Body weight changes with protease inhibitor treatment in undernourished HIV infected patients. Nutrition 15, 453-457.

Semba RD, Miotti PG, Chiphangwi JD, Saah AJ, Canner JK, Dallabetta GA \& Hoover DR (1994) Maternal vitamin A deficiency and mother-to-child transmission of HIV-1. Lancet 343, 1593-1597.

Silva M, Skolnik PR, Gorbach SL, Spiegelman D, Wilson IB, Fernandez-DiFranco MG \& Knox TA (1998) The effect of protease inhibitors on weight and body composition in HIVinfected patients. AIDS 12, 1645-1651.

Stricker RB \& Goldberg B (1998) Weight gain associated with protease inhibitor therapy in HIV-infected patients. Research in Virology 149, 123-126.

Sullivan AK, Feher MD, Nelson MR \& Gazzard BG (1998) Marked hypertriglyceridaemia associated with ritonavir therapy. AIDS 12, 1393-1394.
Suttmann U, Ockenga J, Selberg O, Hoogestraat L, Deicher H \& Muller MJ (1995) Incidence and prognostic value of malnutrition and wasting in Human Immunodeficiency Virus-infected outpatients. Journal of Acquired Immune Deficiency Syndrome 8, 239-246.

Tang AM, Graham NMH, Kirby AJ, McCall LD, Willett WC \& Saah AJ (1993) Dietary micronutrient intake and risk of progression to Acquired Immunodeficiency Syndrome (AIDS) in Human Immunodeficiency Virus type 1 (HIV-1)-infected homosexual men. American Journal of Epidemiology 138, 937-951.

Teixeira A, Leu JC, Honderlick P, Trylesinski A \& Zucman D (1997) Variation in body weight and plasma viral load in HIV patients treated with tritherapy including a protease inhibitor. Nutrition 13, 269 Abstr.

Vittecoq D, Escaut L \& Monsuez JJ (1998) Vascular complications associated with use of HIV protease inhibitors. Lancet 351, 1959.

Wheeler DA, Gibert CL, Launer CA, Muurahainen N, Elion RA, Abrams DI \& Bartsch GE (1998) Weight loss as a predictor of survival and disease progression in HIV infection. Terry Beirn Community Programs for Clinical Research on AIDS. Journal of Acquired Immune Deficiency Syndrome 18, 80-85. 